\title{
VALORIZAR E DIVULGAR A GEODIVERSIDADE: ESTRATÉGIAS DO CENTRO DE REFERÊNCIA EM PATRIMÔNIO GEOLÓGICO CRPG - MHNJB/UFMG
}

\author{
Maria Márcia Magela Machado ${ }^{1}$ \& Úrsula Azevedo Ruchkys ${ }^{1}$
}

\begin{abstract}
RESUMO
O Museu de História Natural e Jardim Botânico (MHNJB) é um órgão suplementar da Universidade Federal de Minas Gerais, direcionado para a investigação científica e atividades de extensão ambiental e cultural, constituindo-se um espaço onde a ciência é exibida e disseminada para o público leigo. O Museu conta com exposições e espaços artístico-culturais relacionados às temáticas de arqueologia pré-histórica e histórica, mineralogia, plantas medicinais, botânica, cartografia histórica e arte ambiental. Com intuito de promover práticas extensionistas significativas e pesquisa no âmbito da geologia, foi criado em 2010 o Centro de Referência em Patrimônio Geológico que tem como um de seus objetivos promover a difusão da geologia e da geodiversidade permitindo a sensibilização do público para a geoconservação.
\end{abstract}

\begin{abstract}
The Museum of Natural History and Botanical Garden (MHNJB) is a part of the Federal University of Minas Gerais - UFMG, and constitutes a space where science is shown and disseminated for a lay public developing scientific research and practical activities of environmental and cultural extension. The Museum counts with expositions and related artistic-cultural spaces focussing on prehistoric and historical archaeology, mineralogy, medicinal plants, botany, historical cartography and environmental art. With the objective to increase the dissemination of geosciences to those citizens, the Center of Reference in Geological Heritage was created in 2010 and has as one of its aims promoting geology, geodiversity and geoconservation.
\end{abstract}

\section{INTRODUÇÃO}

Desde a II Conferência das Nações Unidas sobre Meio Ambiente e Desenvolvimento, conhecida por RIO-92, quando foi adotada a Convenção da Diversidade Biológica, a cobertura midiática sobre a conservação da biodiversidade tem tido um grande incremento com a produção de artigos, livros, páginas web, seminários, workshops, entre outros meios de comunicação. A preocupação principal tem sido o elevado número de espécies, animais e vegetais, que poderão vir a se extinguir dentro de, relativamente, pouco tempo (Nieto, 2004). Uma grande demonstração do alcance mundial desta preocupação ou da consolidação da biodiversidade como objeto privilegiado de ações, políticas e projetos especiais nos meios científicos e acadêmicos, implementados por instituições governamentais e não governamentais em vários países é o fato da UNESCO ter declarado o ano de 2010 como Ano Internacional da Biodiversidade.

Alexandrowicz \& Kozlowski (1999) argumentam que uma abordagem mais holística da Natureza não foi ainda posta em prática, resultando num tratamento desequilibrado entre as suas componentes bióticas e abióticas. No Brasil o quadro não é diferente e, de maneira geral, tem havido uma discrepância em relação à realização de projetos de pesquisa, extensão e educação sobre as duas componentes complementares da natureza, a biodiversidade e a geodiversidade.

Este quadro reflete, em parte, a relativa juventude do termo geodiversidade que foi utilizado pela primeira vez durante a Conferência Internacional de Malvern, Reino Unido, sobre Conservação Geológica e Paisagística, realizada em 1993. Da mesma forma que a biodiversidade corresponde à diversidade da natureza viva, a geodiversidade corresponde à variedade de estruturas (sedimentares, tectônicas, geomorfológicas e petrológicas) e materiais geológicos (minerais, rochas, fósseis e solos), que constituem o substrato físico natural de uma região, o qual suporta a biodiversidade.

Conforme salienta Azerêdo (2008), a geodiversidade é o suporte de todos os sistemas terrestres e, portanto, da biodiversidade, sendo essencial conhecer e compreender o seu valor e o seu papel na dinâmica do nosso Planeta e na própria Vida. Tal deve ser feito numa perspectiva integrada de abordagem científica, extensionista e pedagógica, promovendo o conhecimento sobre os objetos de estudo naturais, em particular os geológicos, sua valorização, preservação e repercussão na sociedade.

Segundo Nascimento et al. (2008), o conceito de geodiversidade está estreitamente relacionado com o conceito de patrimônio geológico, que é representado pelo conjunto de sítios geológicos, ou geosítitios, lugares cujas ocorrências geológicas possuem inegável valor científico, pedagógico, cultural ou turístico. Cortés (1996) define o patrimônio geológico como sendo "um conjunto de recursos naturais não-renováveis, de valor científico, cultural ou educativo, que permitem conhecer, estudar e interpretar a evolução da história geológica da Terra e os processos que a modelaram". A conservação deste tipo específico de patrimônio é 
comumente denominada geoconservação.

Para concretizar o $4^{\circ}$ princípio da Declaração Internacional sobre os Direitos da Memória da Terra (1991): “A nossa história e a da Terra são inseparáveis; a sua origem e a sua história são nossas; o seu futuro será o nosso futuro", é fundamental desenvolver estratégias de geoconservação por meio da divulgação do significado do patrimônio geológico que registra e fornece dados sobre a história de evolução do planeta. Entretanto, estes termos ainda são pouco reconhecidos pela sociedade em geral e, até, por grande parte dos próprios agentes educativos.

No Brasil a importância do patrimônio geológico e a necessidade de sua conservação foi reconhecida, de forma mais efetiva, com a criação da Comissão Brasileira de Sítios Geológicos e Paleobiológicos SIGEP, em março de 1997. Entre as diversas instituições que apóiam a SIGEP estão a Academia Brasileira de Ciências - ABC, a Associação Brasileira para Estudos do Quaternário - ABEQUA, o Departemaneto Nacional de Produção Mineral - DNPM, o Instituto Brasileiro de Meio Ambiente e dos Recursos Naturais Renováveis IBAMA, o Instituto do Patrimônio Histórico e Artístico nacional - IPHAN, o Serviço Geológico do Brasil - CPRM, a Sociedade Brasileira de Espeleologia SBE, a Sociedade Brasileira de Geologia - SBG e a Sociedade Brasileira de Paleontologia - SBP (Ruchkys, 2007). Em termos mundias, um grande avanço no sentido da geoconservação foi o lançamento do Programa Geoparks pela UNESCO, em 1999, que visa distinguir regiões que abrigam um patrimônio geológico relevante e nas quais esteja em prática uma estratégia de desenvolvimento sustentado baseado na geologia e em outros valores naturais e humanos.

Recentemente foram concretizadas duas iniciativas no âmbito da UFMG com o propósito de incentivar esta nova cultura relacionada à geologia em Minas Gerais, um Estado que tem a história de ocupação de seu território estreitamente relacionada a seus recursos minerais, sendo suas paisagens atuais resultado de processos geológicos atuantes durante cerca de 4,6 bilhões de anos de história da Terra. Em meados de 2010 foram criados o grupo de pesquisa em Patrimônio Geológico no Centro de Pesquisas Manuel Texeira da Costa - CPMTC do Instituto de Ciências e o Centro de Referência em Patrimônio Geológico - CRPG como um Centro Especializado do MHNJB. Ambos são parte de um projeto de produção de conhecimento nesta área, sendo que CRPG foi idealizado também com o objetivo de viabilizar que a população em geral tenha acesso a este tipo de informação e perceba a complexidade e o tempo que a natureza levou para construir as paisagens atuais e as valorize.

A difusão do conhecimento geológico é fundamental na promoção da geoconservação: a compreensão do significado do patrimônio geológico em ambientes não formais de ensino pode promover a conscientização do cidadão da necessidade de sua proteção. A sua inserção numa zona urbana, em local aprazível com comodidade de deslocamento, fazem do CRPG um excelente recurso para a realização de ações de divulgação e de ensino da geologia.

\section{OBJETIVOS DO CRPG}

O Museu de História Natural e Jardim Botânico da UFMG é um espaço interativo de divulgação científica, funcionando como plataforma de desenvolvimento científico-cultural por meio da dinamização do ensino-aprendizagem em ciências e com projetos de educação ambiental e patrimonial. Estas atividades são implementadas em conformidade com as diretrizes do Centro de Extensão - CENEX, recorrendo a atividades práticas, interdisciplinares, baseadas na cooperação e na participação, buscando estabelecer relação entre a sensibilização para o meio ambiente, a aquisição de conhecimentos, habilidades e atitudes, visando ainda a elucidação de valores numa perspectiva crítica e reflexiva.

Dentro desse contexto, são objetivos do Centro de Referência em Patrimônio Geológico: propiciar a realização de estudos, inclusive atividades laboratoriais, sobre substâncias minerais, especialmente as gemas; propiciar pesquisas de inventariação de patrimônio geológico; evidenciar o valor científico-educativocultural do patrimônio geológico; promover processos de ensino informal da mineralogia, gemologia e geoconservação, entre outras disciplinas escolares e científicas; contribuir para a mobilização de estudiosos de diversas especialidades e países interessados em explorar as fronteiras desse conhecimento, tornando-o, também, interdisciplinar ou transdisciplinar (Machado \& Ruchkys, 2010).

\section{DIFUSÃO DA GEOLOGIA E DA GEODIVERSIDADE}

O museu é um espaço de produção e divulgação de conhecimento, portanto locus de contato entre a ciência e a sociedade. Trazer à luz descobertas e avanços científicos realizados podem, em diferentes níveis, embasar processos decisórios e gerar uma atitude positiva face à ciência. As múltiplas alternativas para esta interação entre o conhecimento produzido na Universidade e a difusão da ciência, por conseguinte, pelo menos teoricamente, seriam mais facilmente implementadas em museus inseridos no meio acadêmico. Contudo, desempenhar o importantíssimo papel de uma espécie de ponte entre a produção científica especializada e a comunidade, transcendendo as práticas tradicionais de ensino, é um desafio para os professores.

Para Mansur (2009), se existem dificuldades para divulgação da ciência para a sociedade em geral, maiores ainda são os obstáculos para a disseminação de conceitos geológicos normalmente restritos aos meios acadêmicos. Assim, é premente a necessidade de desenvolvimento de projetos educativos ligados 
à geoconservação reconhecendo as ligações entre geologia, solos, habitats, paisagens e processos naturais. No Brasil, as atividades desenvolvidas pelo Projeto Caminhos Geológicos (iniciativa do Serviço Geológico do Estado do Rio de Janeiro, DRM-RJ) podem ser consideradas conscientizadoras e incentivadoras da questão da geoconservação. O projeto está baseado em estratégias de educação, valorização e divulgação do patrimônio geológico por meio da sinalização interpretativa, com produção de painéis, e especial atenção é dada à produção do material educativo no que diz respeito à linguagem e figuras utilizadas.

Para Mateus (2006), aprender Geologia promove a compreensão da singularidade do Planeta Terra, permitindo desenvolver competências gerais e específicas que vão facilitar a compreensão de sistemas sócio-ecológicos, baseados na geodiversidade. A conservação do patrimônio geológico passa necessariamente pela conscientização da sociedade quanto ao seu valor, significado e potencialidades.

\section{ESTRATÉGIAS DE PROMOÇÃO E VALORIZAÇÃO}

Tendo consciência do enorme valor do patrimônio geológico do Estado de Minas Gerais, do ponto de vista da história da exploração mineral e da geodiversidade, quer em nível científico, quer em nível didático, estético e cultural, está em desenvolvimento um conjunto de iniciativas no CRPG no sentido de dar maior visibilidade e tornar acessível a sua compreensão para o público em geral. Estas iniciativas envolvem ações de extensão condizentes com experiências de sucesso já desenvolvidas em Portugal - notadamente o Programa de inovação pedagógica em geociências "Rocha Amiga" (rochamiga.fc.ul.pt).

O Programa "Rocha Amiga" foi criado no âmbito das comemorações do Ano Internacional do Planeta Terra - AIPT (2007-2009) com o objetivo de criar um espaço para o desenvolvimento de atividades, produção de materiais didáticos e novas abordagens que contribuam para a inovação do ensino das geociências. Durante o ano letivo de $2007 / 2008$, este projeto sensibilizou alunos do ensino fundamental para o papel das geociências na sociedade contemporânea, tendo como estratégia a divulgação da função que as rochas desempenham para o bem-estar e desenvolvimento sustentado das populações. Segundo Mário Cachão, idealizador e coordenador da proposta, atualmente o Programa está sendo adaptado e implementado em um grupo inicial de países da Comunidade de Países de Língua Portuguesa (CPLP), nomeadamente Angola, Cabo Verde, Moçambique e Brasil, cuja integração à esta Rede está sendo viabilizada pelo CRPG. Em 2010, foi aprovado pela Fapemig um projeto com o objetivo de desenvolver pesquisas e implementar metodologias e ações sócioeducativas baseadas na experiencia do Programa "Rocha Amiga" sobre três sítios geológicos pilotos da região do Quadrilátero Ferrífero localizados próximos a escolas de ensino fundamental visando sensibilizar a comunidade escolar para a importância científica, didática, paisagística/estética, cultural e socioecônomica do patrimônio geológico de seu entorno.

Outra iniciativa é a concepção da exposição permanente “Jardim Geológico do Quadrilátero Ferrífero". Esta proposta foi desenvolvida em parceria com a Casa da Botânica e o CENEX do Museu de História Natural e Jardim Botânico da UFMG e consiste da produção de exposição de mesmo título, cujo objetivo é levar o conhecimento científico sobre as rochas e plantas do Quadrilátero Ferrífero, em especial daquelas associadas à canga, valorizando e evidenciando as semelhanças entre os diferentes saberes (científicos ou não).

Jardins geológicos podem ser vistos como exposições a céu aberto que guardam amostras de rochas que documentam a evolução geológica de determinada região associadas às características botânicas, visando a pesquisa científica, a conservação, a exibição e a educação. A proposta foi apresentada ao Conselho Consultivo do Museu e aprovada, sua implantação terá início a partir do próximo ano.

\section{CONCLUSÃO}

O conhecimento sobre as rochas, seu contexto evolutivo e sua importância necessitam ser mais difundidos junto ao público em geral em benefício do desenvolvimento sustentável. A introdução do tema, de forma interativa, em museus de ciência é uma forma de despertar o interesse e a curiosidade das pessoas para a compreensão da evolução geológica da Terra e de conceitos como geodiversidade, patrimônio geológico e geoconservação. A existência de um Centro de Referência em Patrimônio Geológico cumprindo este papel é especialmente relevante em Minas Gerais, um Estado que, por sua formação geológica, tem sua história e cultura marcada pelas atividades de mineração sendo, ainda hoje, um dos maiores produtores brasileiros de gemas, ouro e ferro e sede do maior parque siderúrgico e metalúrgico do país. Por outro lado, o destaque de Minas Gerais no cenário mundial não se deve apenas às suas significativas jazidas minerais, mas também pelo seu singular patrimônio geológico constituído por numerosos afloramentos de rochas de excepcional interesse científico e pedagógico que permitem a compreensão dos processos de evolução da história geológica da Terra.

O CRPG tem como propósito oferecer uma estrutura completa para o desenvolvimento de pesquisas em patrimônio geológico, geodiversidade e geoconservação, viabilizando ações nas áreas de ensino e extensão de forma a contribuir para a divulgação dessas riquezas e para conservação deste patrimônio. Com a criação deste espaço pretende-se aproximar o público em geral e especialmente, os professores e estudantes dos Ensinos Fundamental e Médio, da ciência Geologia 
por meio do desenvolvimento de exposições interativas, produção de material didático, cursos, eventos, mostras de vídeos científicos, publicações com utilização de uma linguagem acessível entre outras ações.

\section{AGRADECIMENTOS}

As autoras agradecem à Fundação de Apoio à Pesquisa do Estado de Minas Gerais - FAPEMIG pelo apoio financeiro concedido por meio do Projeto de Pesquisa APQ-03167-10 aprovado no edital de apoio a projetos de extensão em interface com a pesquisa.

\section{REFERÊNCIAS BIBLIOGRÁFICAS}

ALEXANDROWICZ Z. \& KOZLOWSKI S. 1999. From selected geosites to geodiversity Conservation - Polish example of modern framework. In: Barenttino D., Vallejo M., Gallego E. (Eds.). Towards the balanced management and conservation of the geological heritage in the new millenium. Madrid, Spain: Sociedad Geologica de Espana, 40-44

AZERÊDO A. 2008. Apresentação de acção de formação nas modalidades de estagio, projecto, oficina de formação e círculos de estudos, Projeto Pedagógico apresentado ao Conselho cientifico-pegagogico da formação continua. Lisboa, Portugal.

BRANDÃO C.R. \& OLIVEIRA H.T. 2002. A terceira margem do rio - a experiência de. traduzir textos científicos sobre biodiversidade como. material de educação ambiental de vocação biodiversa. Biota Neotropica, v2 (n2) .
CACHÃO M., BRILHA J., MATIAS L., SÁ A. \& LOPES P. 2008. ROCHA AMIGA, Projecto Pedagógico integrado no Ano Internacional do Planeta Terra. Memórias e Notícias, n 3 (Nova Série), Coimbra: 293-300.

CORTÉS A.G. 1996. Inventario del Patrimonio Geológico. In MOPTMA - Min. Obr. Públ. Tranp. Med. Amb. El patrimonio geológico. Bases para su valoración, protección, conservación y utilización. Madrid. Espana.

MACHADO M.M.M. \& RUCHKYS U.A. 2010. Regimento do Centro de Referência em Patrimônio Geológico. Museu de História Natural, UFMG.

MATEUS A. 2006. A Geologia no limiar do século XXI: consolidação de um percurso, projectando o futuro. In: e.Ciência - A Revista da Ciência, Tecnologia e Inovação em Portugal, n 112 , Novembro, Vulcanologia e Geodiversidade, Marcas e Dinâmica da Geologia em Portugal,13-20.

MANSUR K.L. 2009. Projetos educacionais para a popularização das geociências e para a geoconservação. Geol. USP, Publ. espec., vol.5, p.63-74.

NASCIMENTO M., RUCHKYS U. \& MANTESSO-NETO V. 2008. Geodiversidade, geoconservação e geoturismo: trinômio importante para a conservação do patrimônio geológico. Ed. Sociedade Brasileira de Geologia. 82p.

NIETO L.M. 2004. El Patrimônio Geológico: Cultura, Turismo y Médio Ambiente. In: Mondejar, G.M; Jimenez A.D.R. (eds.). Actas de la V Reunión Nacional de la Comissión de Patrimonio Geológico de la Sociedade Geológica de España.

RUCHKYS U.A. 2007. Patrimônio geológico e geoconservação no Quadrilátero Ferrífero, Minas Gerais: potencial para a criação de um geoparque da UNESCO. Tese de Doutorado em Geologia, Universidade Federal de Minas Gerais. 211p. 